\title{
Constructing General Aviation Aircraft in the Aerospace Lab Courses
}

\author{
Daniel J. Biezad, Joon Kim \\ Aerospace Engineering Department \\ California Polytechnic State University, San Luis Obispo
}

\begin{abstract}
The Aerospace Engineering Department at Cal Poly State University, San Luis Obispo, is in the midst of a dynamic experiment to revitalize its "hands on" approach to undergraduate engineering education by introducing aircraft manufacturing and fabrication "kits" into its laboratory curriculum. The challenges and opportunities are many, and the most important are discussed in this paper. They include the enormous difficulty of establishing a recurring lab syllabus for such an endeavor, combined with the lack of faculty expertise in aircraft fabrication that may exist in the department. Traditional projects and grades are also a problem, since failure or sub-standard work to meet any standard for flight is not acceptable. Adequate lab space, resources, specialty tools, and expertise in blueprint analysis are also difficult challenges to meet, especially for the large number of inexperienced students who come into this course at every offering.
\end{abstract}

The way that Cal Poly has been meeting the above challenges is both unique and risky. The recruiting and inclusion of resources from the Federal Aviation Agency (FAA), from industry, from the university, and from local hobbyists to help establish these special lab courses is presented, along with very real concerns about liability and safety. Funding needs and workload on faculty and students are also realistically discussed. Student comment and enthusiasm for the work conclude the paper.

I. The Challenge and the Opportunity

Ideas abound on how to improve technical education ${ }^{1}$ by changing America's culture of teaching. Engineering accreditation teams struggle with how to offer the laboratory experience $^{2}$ so that more can share in the benefits of "hands on" activity. One of the primary goals of engineering practice has always been to link theory with practice, and true-life stories of engineering practice are both interesting and profound. ${ }^{3,4}$ Providing the student with his or her own true-life experience while at the academy increases both the motivation to master a subject and the developing passion for creative activity.

Technical educators bemoan the fact that some, if not many, of our students do not develop this passion for learning or habit for independent, innovative thought that is at the heart of all professional education. ${ }^{5}$ Despite the significant promotion of team activities in engineering colleges, some still view the engineering profession in particular as solitary work in cubicles that consists of reading articles and accessing computer programs for an occasional meeting. This view matches and is reinforced by much of their academic experience in the classroom. The link between theory and practice may be spoken but seldom experienced for these students. 
As shrinking budgets cause an ever greater part of undergraduate laboratory education to be computer centered, and as a greater percentage of students enter the curriculum without practical experience in mechanics or a familiarity with tools and tooling, there is a strong need to expose aerospace engineering students to these realities of the aviation workplace, a workplace that traditionally has inspired a passionate intensity. The Aerospace Engineering Department at Cal Poly is trying to provide hands-on skills and foster this intensity, at reasonable cost, by using special lab courses to construct modern general aviation aircraft (or to construct parts of aircraft) normally offered to the public in "kit" form.

There is surprisingly little information in the technical literature on this subject except for trade publication articles and web site narratives. Isolated projects involving "kit" aircraft, such as the "roadable aircraft," have been described" ${ }^{7,8}$, and NASA funds a program called "AGATE" to revitalize general aviation", but there are no specific guideposts for actually implementing "kit" aircraft into existing aerospace engineering curricula. In a humble spirit, the purpose of this document is to provide a few of these guideposts.

\section{I.1 Course Objectives}

It has been important from the outset that the course strive for more than merely turning students into kit builders, though that may certainly be one of the outcomes. Here are the official course objectives of Aero 572, Aircraft Manufacturing and Fabrication, that is offered two quarters of every academic year:

"The objectives of this course are to provide a hands-on demonstration and practice of the techniques used in aircraft manufacturing and fabrication. This may include, but is not limited to, seminar topics, field trips to aircraft designers, and actual construction of an aircraft. The primary purpose of the course is to compliment the capstone aircraft design sequence and give selected students significant exposure to aircraft fabrication techniques. By its nature this requires a team orientation, exposure to most if not all engineering disciplines as they relate to flight, and a systems view of planning, task scheduling, documentation, and testing.

Students completing this course will be able to: (1) explain fundamental manufacturing and fabrication techniques used for aircraft made of metal or of composites; (2) implement the types of fabrication processes used by industry and by small aircraft builders, and document their own progress using established procedures; (3) demonstrate expertise in reading aircraft plans and construction diagrams, especially as the complete aircraft comes together; (4) analyze how modifications and errors impact fabrication time and cost; (5) integrate aircraft construction with FAA certification, safety, systems testing, and (if appropriate) flight simulation." These objectives conform to what is often called Bloom's taxonomy of learning (see Appendix). ${ }^{10}$ 


\section{I.2 Course History}

This laboratory course is unique in that it was student initiated and funded at Cal Poly starting in 2003. In many ways a "perfect storm" of funding, available expertise, and student interest developed at that time allowing a unique opportunity quest. A few individuals in the aerospace program asked the department chair to consider offering an aircraft manufacturing and fabrication class that would give students much needed hands-on experience in working with the structural components, fabrication techniques, control surfaces, and avionics on small aircraft, specifically an RV-7 "kit" aircraft offered by Van's Aircraft in Oregon.

Since the drawings, structural components, controls, and flight systems of the RV-7 are stateof-the-art in many respects, and since the concepts (structures, control, propulsion) relative to educational value apply to larger and more expensive aircraft, the department decided to offer this largely student-initiated and funded course in the 2003-04 academic year and received prompt approval from appropriate university committees. It is important to emphasize that without student interst, involvement, and funding that this course would not have been started by faculty, college, or university initiative. The course is a credit to the initiative, creativity, and technical talent of our student population. Since its inception the course has received wide support from the Industrial Advisory Board of the Aerospace Engineering Department.

For the initial course offerings students would show up at the workplace (rented hangar) after some rudimentary classwork. There they were divided into teams and worked on whatever needed to be done. Work was documented on large dry-erase boards by the team leader. Based on the experiences and problems described in the following section of this paper (labelled "Reality Sets In" below), the currently-used laboratory study guide and project management were greatly revised from those that existed in the initial course offerings. Students now are exposed to a much more structured environment, receive extensive preparation in the class room, and must earn the right to work on the aircraft at the hangar lab location.

Each course offering now consist of three relatively well-defined major parts. In the first part basic skill sets are expected from the students, including familiarity with appropriate tools, shop safety procedures, and expertise in reading plans. In the second part of the course student teams actually build duplicate wing sections from plans accompanying a "training kit." The training kit is supplied by Van's Aircraft in Oregon and is designed specifically to provide the hands-on skills that students need. Students who do poorly on the second project must redo that project and take a written in-class final exam. On the other hand, students who excell on this second project are allowed to propose a final team task or set of tasks that involve working on the aircraft. This is done in lieu of a written final exam and results in either an "A" or an " $F$ " grade for the final project. The department technician, a licensed aircraft mechanic, must approve the final work before it is signed off and documented. 


\section{I.3. Reality Sets In}

PROBLEMS WITH INITIAL COURSE OFFERINGS: Student work on many tasks was rushed and unsupervised. Many students showed up at the hangar without the skills to competently use the tools needed to build aircraft. Inadequate documentation, poor planning, and a lack of attention to the aircraft plans greatly hindered progress. Much work was redone in the summer months between course offerings.

SOLUTION IMPLEMENTED IN CURRENT COURSE OFFERINGS: Before students are allowed to work on the actual aircraft, they must demonstrate skill with fabrication tools and processes to the senior course advisor. Those who are not allowed to work on the aircraft either work on an aircraft simulator project that uses parts unfit for flight or take substitute exams. Senior advisors are skilled students who are earning special credit for being fabrication team leaders. A design review is required for all projects working on the aircraft. Student teams are expected to demonstrate a familiarity and understanding of the plans and of the "lessons learned" by other aircraft builders. Actual work on the aircraft is either " $\mathrm{A}$ " or "F" and must be certified as acceptable by a licensed aircraft mechanic.

\section{Course Content}

Although the main topic for the course is listed in the catalog, the actual contents depend on the status of aircraft construction. All these courses, regardless of topic title listed in the catalog, cover the same basic information through the mid-term exam. This includes familiarity with aircraft materials and construction techniques, exposure and practice to tools, especially those unique to working on aircraft, lab safety procedures, and demonstrated expertise in reading plans and construction diagrams. Each quarter the Aero 572 lab course cycles through one of the topics in the subtitle list below:

1. Cockpit Systems Integration

2. Primary Structural Components

3. Lift and Control Surfaces and Linkages

4. Engine Systems Integration

5. Flight Qualities: Performance

6. Handling Qualities and Testing

7. Avionics Systems Integration

8. Inspections and Certification

9. Human Factors Integration

10. Maintenance, Repair, and Modifications

\section{II.1 Three Projects}

There are three projects in each course. They are described as follows:

PROJECT 1: This project provides the students with a familiarity with tools and basic metalworking fabrication. Students demonstrate fabricating and connecting small metal parts, 
reading plans, and documenting their work. Student teams receive their own tools and tool box for this project and become proficient in riveting (see Figure 1).

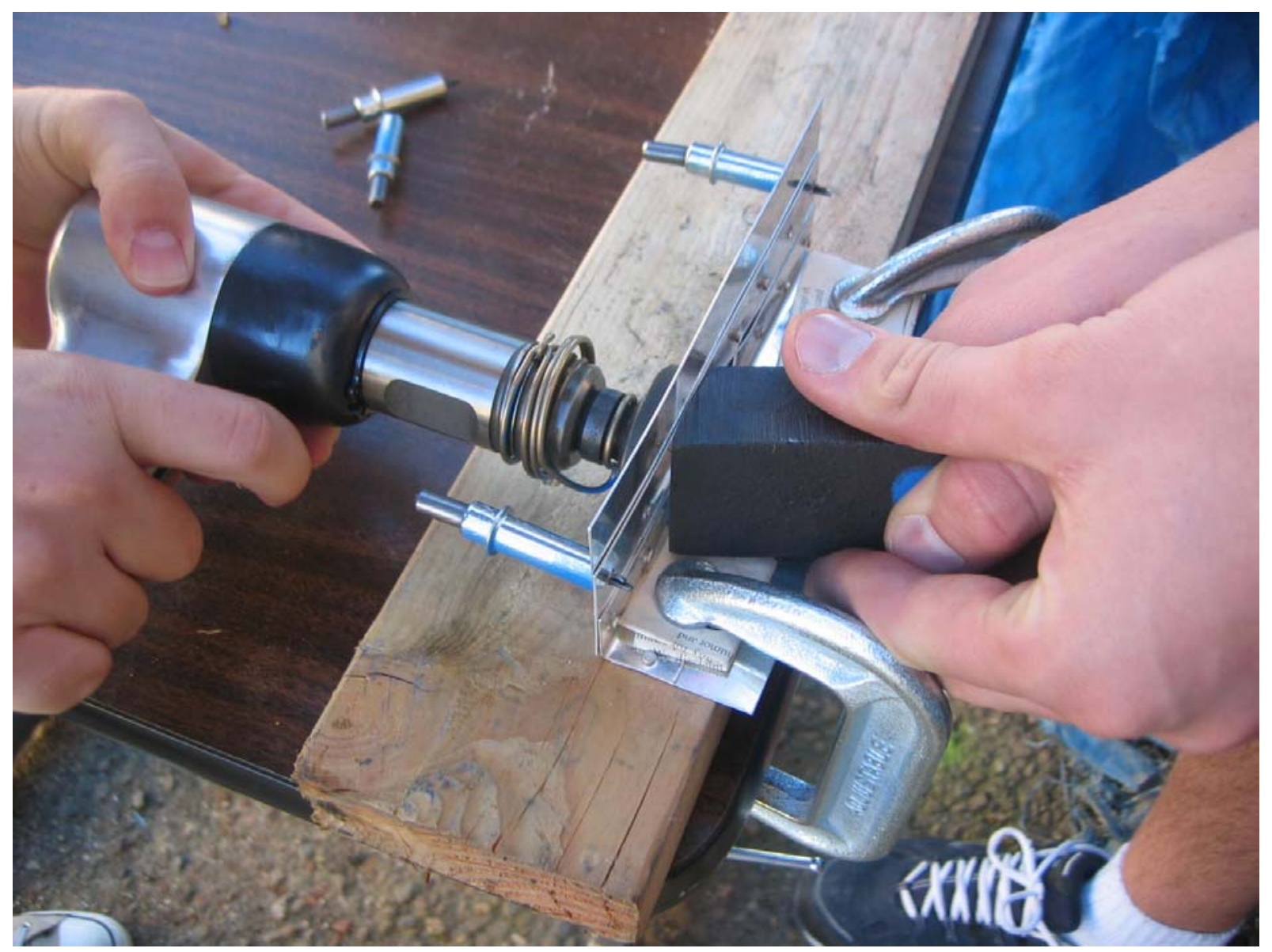

Figure 1 Students Demo Flush Riveting with a Bucking Bar in Project \#1

PROJECT 2: The student is expected to demonstrate skills in the second project. It consists of the construction of a stiffened wing section from plans and associated documentation that are provided in a training kit by Van's aircraft. The instructions for this project are as follows:

\section{PROJECT \#2}

\section{METAL WING SECTION FABRICATION AND CONSTRUCTON}

A. Protection (Eyes and Ears), Partners (No Working Alone), Phone (available)

B. Read and Initial that you have read the material to the left of the instructions

C. Preview the photos available on the class web site for this project

D. Date the log when each sub-task is completed (also at the left of the instruction)

E. Take the completed project to the instructor with your documentation log for grade 
The goal of Project \#2 is to enable the student to competently work on an aircraft fabrication task and to document it thoroughly. It is imperative that the student integrate all that has been learned in Project \#1 and that work not be hurried. The plans are more difficult to read in this project and demand insight and planning. There is important detail in every label, view, and dimension on the plans. Figure 2 shows students receiving a grade for Project \#2.

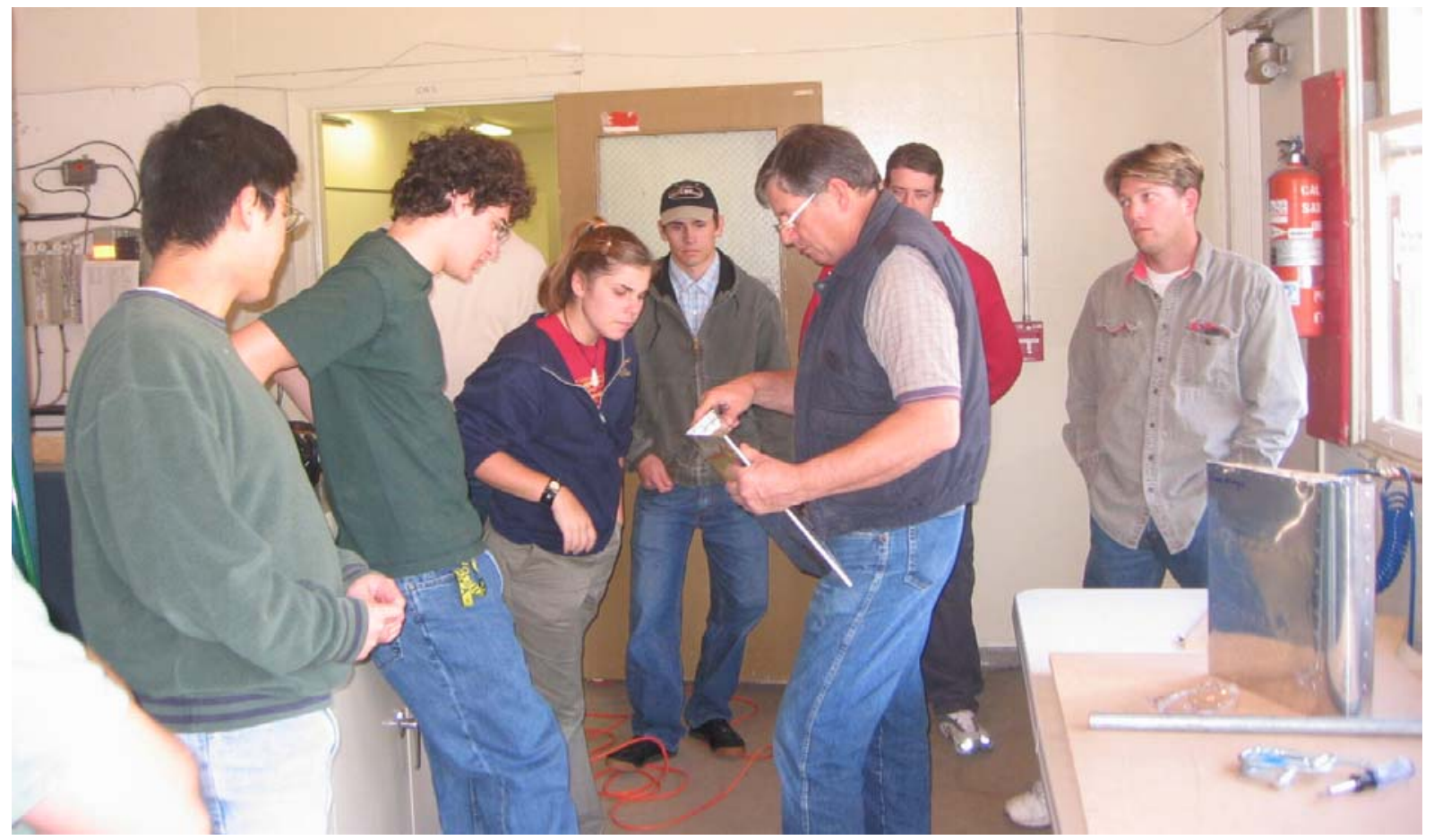

Figure 2 Lab Technician Assigns Grade for Project \#2 (Another Wing Section is on Table at Right)

PROJECT 3: Students who do not demonstrate acceptable skills with tools in Project 2 are required to complete a written in-class final exam. Students showing acceptable skill in aircraft fabrication are invited to present a proposed project and, if approved, will be allowed to work on an actual RV-7 project. The grade for these students will be "A" or "F" for the final project (a licensed aircraft mechanic will be the evaluator). Figure 3 shows work on the actual empennage of the RV-7 aircraft.

\section{II.2 Schedule}

Weeks 1-3: The introduction to the course includes safety briefings, an overview of the aircraft plans, shop and emergency procedures, and team assignments. Students are also introduced to tools and tool management, blueprint reading examples and demonstrations of proper tool use for fastening and for riveting.

Weeks 4-5: This part of the course includes Project \#2 (documented) and a mid-term exam on theory appropriate for the current aircraft fabrication tasks. Students are expected to read the RV-7 documentation appropriate to the current status of aircraft work. 


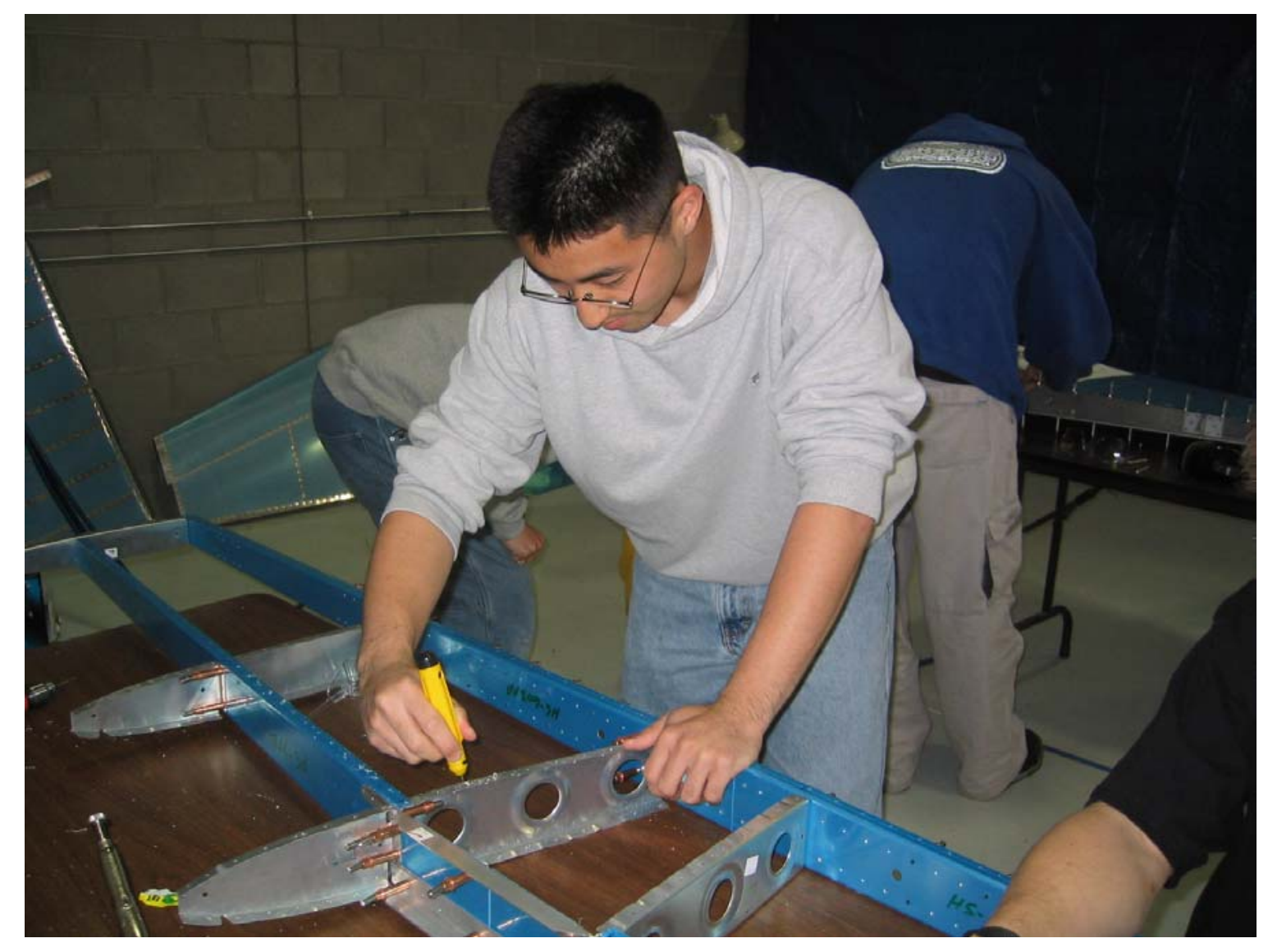

Figure 3 Student Works on the Empennage of the RV-7 Aircraft in Project \#3

Weeks 6-9: Students read and study plans and blueprints for their proposed project. They prepare and present a "design review" with a senior mentor and accomplish work at the hangar. The final work is evaluated by a licensed aircraft mechanic. Students prepare and submit a final report with documentation suitable for submission to the inspectors who will eventually certify the aircraft.

\section{Resources}

There are two absolute essentials for a faculty member attempting this type of endeavor. First is tenure! The second is a relatively independent source of secure funding. Today's university system seeks out and rewards faculty who obtain funded projects that result in publishable results in reputable journals, period! Except for some interesting research done at NASA Langley on general aviation aircraft (and now NASA Lewis for general aviation propulsion), there is little funded work in this area. Kit costs can be expected to approach $\$ 25,000$ (the engine can be expected to cost this much as well). Without enough funds the project will soon become a heap of parts awaiting disposal. Cal Poly is fortunate that the students, if only for a brief time, controlled enough funding to allow purchase of the required kits and engine. This was done by a self-imposed tuition increase intended to improve the quality of their education, and to my knowledge this type tuition increase is a unique event in the academic world. 
Workspace is essential. Once again the modern university environment or research park will provide space for funded projects, but not for building "kit" aircraft. Cal Poly addressed this issue by using some of the student-fee tuition increase for off-campus facilities. First a commercial building was rented, and then as the project progressed a hangar replaced the rented building space. Now the first two projects are done on-campus in space shared by the controls and water tunnel labs. The final project is accomplished at the rented hangar.

Tool lists, compressors, and storage shelves are well described on web sites of aircraft builders, and one that must be mentioned is Van's site (www.vansaircraft.com/public/rqdtool.htm) since it is particularly valuable and informative. Each student team received tools and a tool kit that they were responsible for during the quarter. A list of the included items may be seen at the web site http://aerosrv.atl.calpoly.edu/dbiezad/Aero Courses/Aero 572/ that also contains other useful information about this course at Cal Poly. Approximately $\$ 800$ per toolkit was spent for each student team. The best text for the course is the set of plans and accompanying text available in binder form from Van's aircraft. ${ }^{11}$ Other excellent books on aircraft construction are listed at the end of the bibliography. ${ }^{12-17}$

Many web sites have data that is extremely useful. For the RV-7 aircraft one such site is located at Dan Checkoway's web site http://rvproject.com/ that contains information also sold as a CD. The Experimental Aircraft Association (EAA) has an informative site at http://www.eaa.org/education.html Finally, donations were solicited from industry sources and contacts. Cal Poly received a donated pitot tube assembly and engine manifold cover.

\section{Integrating the Course into the Curriculum}

It is one thing to be lucky enough for a "perfect storm" of funding, expertise, and student interest, and quite another to integrate the resulting course into the curriculum on an ongoing basis. The first step is to obtain special status for this course so that a student can take different subtopics for credit under the same course number and title, as described in section II above. The next step is to allow special credit at either undergraduate or graduate level for specialized, experienced students who will help you train newcomers and assist on final projects. At Cal Poly a senior project is required. This is a two-course sequence that must be defined by the student. These projects are ideally suited to the ongoing development of the aircraft. Special projects at Cal Poly in this area have included installing stress sensors in the wing, designing a low-drag cover for the engine, and designing flight test instrumentation for eliminating propeller drag during glides. ${ }^{7}$

Finally, there must be a steady stream of students with varying degrees of experience to tap for assistance, either as teaching or lab assistants. Cal Poly has had such a stream of talented students in its flight simulation facility for years, and in these times of declining budgets a talented student is a very good bargain indeed!

\section{IV.1 Safety and Liability}

An accident, especially a careless one, may immediately end a project of this type. Safety must be constantly emphasized to the youth of today. Anticipate their feelings of 
invulnerability. At Cal Poly students are asked to remember "triple P" for safety: Protection (Eyes and Ears), Partners (No Working Alone), Phone (available for emergencies). They are reminded that students working off-campus may need to come back on-campus to be covered by university medical insurance. Dialing "911" off-campus in situations that are not lifethreatening may get students transported far from campus for routine treatment.

The aircraft being built is experimental. The FAA will certainly stop an obviously dangerous one from flying, but there are no guarantees that the FAA certificate means the aircraft is safe. The FAA will demand that a builder be named for the aircraft even though it is university property. They expect that $51 \%$ of the aircraft or more will be put together by the direct involvement of this builder (this is the 51-49 rule). Because of this the liability office of the university must be involved from the inception of this project. Verify that the aircraft will be covered for flights involving university courses, faculty, and students. Restricting the aircraft to daytime, visual flight rules (VFR) with an civilian instructor as pilot-in-command should makes insurance rates reasonable. Cal Poly requires that the department carry an added liability policy.

Note that if the aircraft is ever sold and involved in a subsequent accident, the university and all involved may be hard-pressed to avoid involvement in lawsuits. The best procedure to follow in this case is to intentionally sell the aircraft in pieces that are specifically labelled "not for flight!" This gives the builder and the university maximum protection against future legal action.

\section{IV.2 Student Competence and Workload}

Cal Poly was blessed at the initiation of this course with gifted student aircraft builders with much experience. These students provide initial expertise that is usually lacking in resident faculty. They also provide contacts with other builders in the area, and especially with the Experimental Aircraft Association. Expect students with no appreciable skill to advance rapidly if they maintain their enthusiasm for the project.

Student workload is a serious concern. Working on the aircraft is time-intensive and requires concentrated effort. Students working in this area may be funded as teaching or lab assistants, and many who are able may work on the aircraft in the summer months and on break. Perhaps someone may be concerned about faculty workload? Don't ask! Just assume that it takes a bold and intrepid nature to pursue this type of project. Kit builders commonly state that on the home front it is important to let a spouse know about plans of this type and to invite a spouse to be involved as much as practical.

\section{Lessons Learned and Being Learned}

The primary driver for this type of project--student enthusiasm--can also lead to its evil twin-impatience. This generation of students is visual, focused, controlled, and accustomed to being pampered. They also, as nearly every educator will attest, have a short attention span. One can easily be swept away by initial student enthusiasm and end up alone in a sidecanyon with a few stragglers when students realize the aircraft may not fly a few weeks from 
the time they first set their hands on it. Expect a let down between quarters and compensate with field trips, guest lecturers, even fly-ins and an occasional cookout.

Involved faculty should resist the temptation to just go out and "work on the aircraft." The course deserves to be structured properly and ensure that students are prepared before they work on the aircraft, including the difficult task of reading aircraft plans and completing proper documentation. Any work on the aircraft should be pre-briefed to both the responsible faculty and the licensed mechanic. The briefing content should illustrate a good understanding of the aircraft plans and of lessons learned by other aircraft builders.

\section{V.1 Documentation}

Faculty should demand all work be properly documented. Here is a sample log entry:

Aircraft Section: Wing (Section 7) Date: 12/27/04

Workers: Robert Rivera, Joon Kim

Work Done: The Right Leading edge was attached to the right main wing. Not completed. 14 Rivets used, 9 AN470AD4-5 and 5 AN470AD4-7. The interior spars are difficult to rivet because of low visibility and accessibility, so the interior spars are not yet attached. One rivet hole on out most spar not used because the hole is slightly oblong from drilling out rivets, looking into options for this hole and interior spar attachment.

Parts Used: Right Main Wing Assembly, Right Leading Edge Assembly

Working on simultaneous parallel projects must receive special treatment. Plans must detail how the groups will be organized after a thorough review of the aircraft plans for a major component. Below is the flow chart developed for parallel tasks involving fuselage construction. All items in a row must be completed before starting a task the next line down.

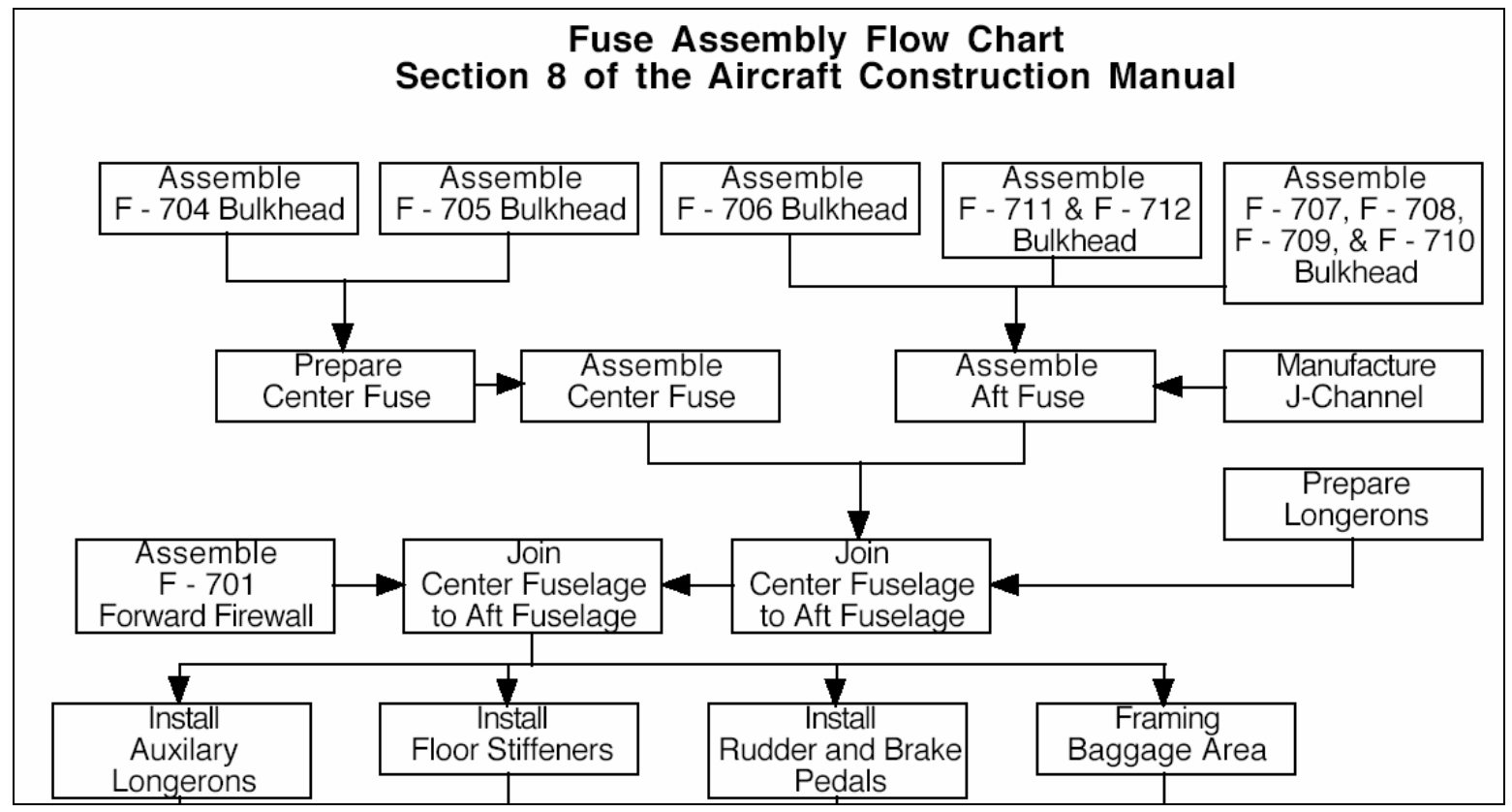

Figure 4 Fuselage Assembly Flow Chart 
The aircraft fabrication tasks should be related to other course work in aerospace, especially in the structures, propulsion, and stability and control areas. Avionics, mechanical systems, materials engineering are all inherently embedded in building a modern general aviation aircraft.

The final project must be set up as " $\mathrm{A}$ " or " $\mathrm{F}$ " because the student has been conditioned in other courses to expect a grade for level of effort and the resulting product appropriate for an investment of a given amount of time. A flight-worthy aircraft simply must be an "A," and those students not willing to risk this investment should choose the conventional in-class written exam as an alternative.

V.2 Comments from students who have taken this course:

"Since this was a unique challenge that we took from the beginning, a lot of invaluable lessons have been learned throughout the course of trial and error and adjusted the course for future considerations. It should be emphasized that the lessons and skills learned from working on this project far exceeds my expectation as it has taught me great deal about kit building, exposed me to many different approaches to solve a unique problem that has stumped many students and taught me the engineering practices performed on this particular aircraft as practiced in bigger industries."

"In a classroom environment, the instructor would discuss certain topics and try to explain to students what certain features of aircraft and their functions were using drawings and pictures. However, the hands-on approach to this kit airplane gave many of the students the chance to see the inner structures of how aircraft are built, how the loads are carried to main structures, why certain features were designed the way they are. All these would not likely have been discussed in a classroom environment nor had the impact."

"Working on an actual kit aircraft exposed us to the many different types of structures that are used to build an aircraft. We were able to identify different parts of the aircraft and understand the interaction between different types of control surfaces and how it affects the flight of an aircraft. We continue to learn new ways to solve problems trying different methods and that puzzle us with all types of real-world problems faced by real engineers."

"As a student, I have greatly benefited from working on a kit airplane as part of the lab courses. Over the years, I have managed and worked on interesting projects from autonomous helicopter to building a re-usable rocket booster, but I was extremely excited and when I heard about the aircraft construction course being offered at Cal Poly, I took the course and I have not regretted it." 
Appendix

\section{Taxonomy of Educational Objectives: Cognitive Domain*}

1. Knowledge - repeating information verbatim. [Examples: list the first ten alkanes; state the steps in the procedure for calibrating a gas chromatograph.]

2. Comprehension-demonstrating understanding of terms, concepts, and principles. [Examples: explain in your own words the concept of vapor pressure; interpret the output from a strip chart recorder or potentiometer.]

3. Application-applying concepts and principles to solve problems. [Examples: calculate the probability that two sample means will differ by more than 5\%; solve the compressibility factor equation of state for $P, T$, or $V$ from given values of the other two.]

4. Analysis - breaking things down into their elements, formulating theoretical explanations or mathematical or logical models for observed phenomena. [Examples: interpret discrepancies between a predicted experimental response and the measured response; model the dynamic performance of a laboratory stirred-tank reactor.]

5. Synthesis-creating something, combining elements in novel ways. [Examples: formulate a modelbased control algorithm for the process studied in last week's lab experiment; make up a homework problem involving material covered in class this week; design a concrete canoe or solar-powered car.]

6. Evaluation - judging the value of material, choosing from among alternatives and justifying the choice using specified criteria. [Examples: select from among available options for measuring an experimental system response and justify your selection; critique a lab report.]

Bibliography

1. Stigler, J.W., and J. Hiebert, The Teaching Gap: Best Ideas from the World's Teachers for Improving Education in the Classroom, 1999, The Free Press, New York, New York.

2. Feisel, L.D., and G.D. Peterson, "A Colloquy on Learning Objectives for Engineering Education Laboratories," Proceedings of the 2002 American Society for Engineering Education Annual Conference \& Exposition, 2002, ASEE, San Diego.

3. Florman, S. C., The Existential Pleasures of Engineering, $2^{\text {nd }}$ Edition, 1976, St. Martin's Press, New York, New York.

4. Petrosky, H., To Engineer Is Human : The Role of Failure in Successful Design, $1^{\text {st }}$ Vintage Books Edition, 1992.

5. Karp, W. and L. Lapham, Buried Alive: Essays on Our Endangered Republic, Franklin Square Press January, 2003.

6. Percy, W. and P. H. Samway, Signposts in a Strange Land, Picador Press, 1992.

7. Kettering, M. L., and D. J. Biezad," A Performance Prediction Tool for General Aviation Flight

Management," Presented at the American Institute of Aeronautics and Astronautics Guidance, Navigation, and Control Conference, Boston, MA., August 10-12, 1998.

8. Kettering, M., Biezad, D.J.,"The Roadable Aircraft Design Project," 6th AIAA Symposium on Multidisciplinary Analysis and Optimization," Bellevue, Washington, Sept. 4-6, 1996.

9. “AGATE—Revitalizing General Aviation,” FS-1997-007-02-LaRC, July 1996.

10. Krathwohl, D.R. and B. S. Bloom, Taxonomy of Educational Objectives, Cognitive Domain Handbook, Longman, New York, 1984.

11. RV7/7A Plans, Van's Aircraft, Aurora, Oregon, 2002.

12. Rhodes, Stress Without Tears, 1998.

13. Meggson, Aircraft Structures for the Engineering Student, Elsevier, 1998.

14. AC 43-13-1B and AC 43-13-2A, FAA publication (Advisory Circulars), 2002. 
15. Reithmaier, L., Standard Aircraft Handbook for mechanics and technicians, McGraw Hill publishers, 1999

16. Bingelis, A., Firewall Forward, EAA Publishing, 1996.

17. Bingelis, A., Sport plane Construction Techniques, EAA Publishing, 1998.

Biography

DAN BIEZAD

Dan Biezad is a professor in the Aerospace Engineering Department at California Polytechnic State University, San Luis Obispo. He is an Associate Fellow of the AIAA, a Senior Member of the IEEE, and has authored a book published in the AIAA Education Series titled "Integrated Navigation and Guidance Systems." Dr. Biezad is also a former pilot instructor at the USAF Test Pilot School, Edwards Air Force Base, California.

\section{JOON KIM}

Joon Kim is a graduate student in the Aerospace Engineering Department at California Polytechnic State University, San Luis Obispo. His home is in Bakersfield, California. 